\title{
Plantas ornamentais no Jardim Botânico FLORAS
}

\author{
Ornamental plants in the FLORAS Botanical Garden
}

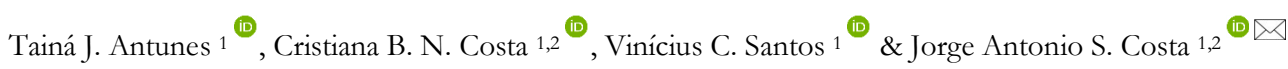

1. Centro de Formação em Ciências Ambientais, Universidade Federal do Sul da Bahia, Campus Sosígenes Costa, Porto Seguro, Bahia, Brasil

2. Núcleo de Pesquisa em Conservação da Flora, Biologia Evolutiva e Sustentabilidade (ConBioS), Porto Seguro, Bahia, Brasil

\section{Palavras-chave}

Floresta dos Tabuleiros. Vegetação. Conservação da biodiversidade. Conservação ex situ. Plantas com potencial ornamental. Flora da Bahia. Remanescente florestal. Extremo Sul da Bahia. Mata Atlântica.

\section{Keywords}

Forest of Tabuleiros. Vegetation. Biodiversity conservation. Ex situ conservation. Plants with ornamental potential. Flora of Babia. Forest remnant. Extreme South of Babia. Atlantic forest.

\section{Doi}

doi.org/10.33447/paubrasilia.v3i2.35

Recebido em: 15/02/2020

Aceite em: 09/07/2020

Editor responsável: Jaílson S. de Novais (UFSB)

ISSN: 2595-6752

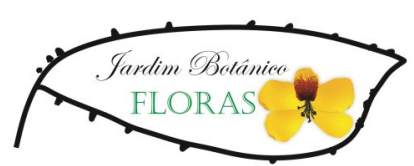

\section{Resumo}

Um jardim botânico é um espaço que proporciona a conservação ex situ da biodiversidade, mantendo plantas vivas. O Jardim Botânico FLORAS (JBFLORAS) ocupa o campus Sosígenes Costa (CSC) da Universidade Federal do Sul da Bahia (UFSB) e possui um remanescente de Mata Atlântica. O trabalho foi desenvolvido no CSC da UFSB, em Porto Seguro, Bahia, Brasil, área antes ocupada pelo Centro Cultural e de Eventos do Descobrimento. Foram realizadas coletas nos jardins do campus e na mata no período de março/2017 a fevereiro/2018. As plantas foram herborizadas e incorporadas ao herbário Prof. Geraldo C. P. Pinto (GCPP). Foram identificadas 86 espécies de plantas ornamentais distribuídas em 78 gêneros e 39 famílias. As famílias mais diversas em número de espécies foram: Arecaceae e Leguminosae (seis espécies); Asparagaceae, Bignoniaceae e Orchidaceae (cinco espécies); e Araceae, Bromeliaceae, Myrtaceae e Rubiaceae (quatro espécies). O hábito predominante foi o herbáceo (29 espécies), seguido pelo arbóreo (25 espécies) e arbustivo (20 espécies). Foram levantadas 10 espécies de plantas nativas com potencial ornamental presentes no fragmento de Mata Atlântica do JBFLORAS. A maior parte das espécies cultivadas (53,5\%) tem origem exótica e 46,5\% são nativas da Mata Atlântica. Sugere-se a introdução de outras espécies nativas aos espaços do Jardim Botânico no intuito de enriquecer a conservação ex situ e valorizar o uso das plantas nativas.

\footnotetext{
Abstract

A botanical garden is a space that provides ex situ conservation of biodiversity, keeping living plants. The FLORAS Botanical Garden (JBFLORAS) occupies the Sosigenes Costa campus (CSC) of the Federal University of Southern Babia (UFSB) and has a remnant of the Atlantic Forest. The work was carried out at the CSC-UFSB, in Porto Seguro, Babia, Brazil. This area was previously occupied by the Centro Cultural e de Eventos do Descobrimento. Collections were carried out in the campus gardens and forest from March/2017 to February/2018. The plants were herborized and incorporated to the Prof. Geraldo C.P. Pinto (GCPP) Herbarium. Eighty-six species of ornamental plants were identified, distributed in 78 genera and 39 families. The most diverse families in number of species were: Arecaceae and Leguminosae (6 species); Asparagaceae, Bignoniaceae, and Orchidaceae (5 species); and Araceae, Bromeliaceae, Myrtaceae, and Rubiaceae (4 species). The predominant habit was herbaceous (29 species), followed by arboreal (25 species), and shrub (20 species). Ten native plant species with ornamental potential present in the Atlantic Forest fragment of JBFLORAS were surveyed. Most of the cultivated species (53.5\%) are of exotic origin and $46.5 \%$ are native to the Atlantic Forest. It is suggested to introduce other native species to the Botanical Garden in order to enrich ex situ conservation and enhance the use of native plants.
} 


\section{Introdução}

Desde séculos passados, o cultivo de plantas ornamentais está presente em diversas sociedades (Felippe; Zaidan, 2008). O processo de globalização dos costumes, iniciado no final do século $\mathrm{XX}$, culminou em uniformização na aparência dos arranjos florais e jardins, que passaram a empregar praticamente as mesmas espécies em diversas regiões do globo. No Brasil não foi diferente e, desde o período colonial, a ideia de beleza associada ao exótico predominou. Utilizar plantas vindas do exterior era sinal de riqueza entre os habitantes, ainda que a biodiversidade vegetal nativa encantasse grandes artistas e cientistas (Heiden et al., 2006; Dourado, 2009). A presença de imigrantes também contribuiu para a disseminação de espécies exóticas cultivadas, uma vez que estrangeiros recém chegados procuravam reproduzir ambientes mais familiares ao cultivarem as plantas medicinais e ornamentais dos seus países de origem (Veiga et al., 2003; Stumpf et al., 2009).

Atualmente, sabe-se que as plantas ornamentais, além de serem cultivadas por suas belezas e cores, sendo apreciadas na arquitetura de interiores e no paisagismo de áreas externas, quando adequadamente manejadas, podem garantir a conservação genética e cultural de tais espécies (Heiden et al., 2007). A valorização das diversidades locais também está transformando as aparências dos jardins, e o reconhecimento da flora nativa tem ganhado força no atual contexto histórico (Romano et al., 2009). O arquiteto e paisagista Roberto Burle Marx foi o precursor do interesse pela flora brasileira no âmbito da ornamentação, utilizando as espécies nativas de forma ampla em seus trabalhos, integrando a natureza local e associando espécies tropicais (Veiga et al., 2003; Heiden et al., 2006; Romano et al., 2009).

Segundo Pinto e Graziano (2003), estudos têm sido realizados na perspectiva de se descobrir espécies nativas que podem colaborar no desenvolvimento da floricultura nacional, proporcionando desenvolvimento, abertura de novos mercados e preservação. Além disso, a utilização de espécies nativas pode garantir a manutenção de serviços ecossistêmicos essenciais e a preservação em bancos de germoplasma vivo dessas espécies em áreas verdes das cidades (Salvador, 2018).

Estudos mostram consequências ambientais, econômicas e sociais negativas sobre o cultivo de espécies não nativas (alóctones ou exóticas), tanto em jardins como no ambiente natural (Randall; Marinelli, 1996; Schmitz et al., 1997; Ziller, 2001; Randall; Reichard, 2002). Por outro lado, o uso de espécies nativas (autóctones) para ornamentação tem alcançado destaque positivo por contribuir para a conservação da flora local e ser economicamente eficiente, necessitando de pouca manutenção e proporcionando diversidade de habitats para a vida silvestre local, reforçando as identidades regionais (Buckstrup; Bassuk, 1997).

Enquanto polos educativos, científicos e até econômicos, os jardins botânicos são espaços multiculturais importantes para a preservação, a valorização e a difusão da memória e da identidade brasileira (Willison, 2003). Desempenham um papel vital na preservação das espécies vegetais, em uma perspectiva de desenvolvimento sustentável no meio urbano, alcançando imensa importância no planejamento regional (Almeida et al., 1999; Peixoto; Willison, 2003; Guedes-Bruni, 2010). Para isso, a sistematização de informações de um jardim botânico deve estar de acordo com as Diretrizes para Desenvolvimento de Estratégias Individuais de Educação Ambiental nestes espaços (Willison, 2003). Para ser um recurso valioso de ensino, é preciso que haja no jardim informações claras disponíveis sobre seu acervo. Deste modo, é necessária uma exposição interativa de informações seguras, como espécies de plantas que compõem um jardim, suas origens, usos, principais adaptações, a importância em determinadas culturas, entre outros aspectos que requerem o conhecimento da diversidade botânica e as relações históricas atreladas a cada planta (Willison, 2003).

Assim, o estudo e a catalogação das espécies vegetais ornamentais presentes em Jardins Botânicos são fundamentais para ampliar o conhecimento sobre os impactos ambientais, no caso de espécies exóticas, suas relações ecológicas e a importância etnobotânica destas espécies cultivadas para fins ornamentais (Willison, 2003). Da mesma forma, a sinalização de espécies nativas com potencial ornamental auxilia no processo de conservação e valorização da flora local, contribuindo para a ampliação do uso de espécies nativas no paisagismo brasileiro (Lorenzi; Souza, 2015).

O Jardim Botânico FLORAS (JBFLORAS) foi instalado no Campus Sosígenes Costa (CSC) da Universidade Federal do Sul da Bahia (UFSB), local onde anteriormente funcionava o Centro Cultural e de Eventos do Descobrimento (CCED), conhecido como Centro de Convenções de Porto Seguro. A construção do Centro de Convenções ocorreu nos anos 2000 em comemoração aos 500 anos do Brasil e foi local de terraplanagem, abertura e calçamento de vias de acesso e estacionamentos, além da introdução de diversas espécies ornamentais no paisagismo dos jardins e canteiros centrais. Atualmente, o Campus Sosígenes Costa da UFSB possui três fragmentos de Mata Atlântica em regeneração natural desde o ano 2000, mas que ainda passam por fortes pressões antrópicas, como a implantação de novas instalações acadêmicas e de pesquisa da universidade (Pinto et al., 2019).

O objetivo deste trabalho foi listar todas as espécies cultivadas no Jardim Botânico FLORAS (JBFLORAS) e contribuir na indicação de espécies nativas da flora local com potencial ornamental.

\section{Material e Métodos}

Área de estudo

A área do Jardim Botânico FLORAS fica dentro do Campus Sosígenes Costa (CSC) da Universidade Federal do Sul da Bahia (UFSB), localizada no município de Porto Seguro, Bahia, com coordenadas centrais de $16^{\circ} 25^{\prime} 22,90^{\prime \prime} \mathrm{S}$ e $39^{\circ} 08^{\prime} 11,56^{\prime \prime} \mathrm{O}$, a aproximadamente $75 \mathrm{msnm}$ (Figura 1). A área possui $232.000 \mathrm{~m}^{2}$, sendo aproximadamente $20.000 \mathrm{~m}^{2}$ de área construída. O Centro Cultural e de Eventos do Descobrimento (CCED) foi cedido em 2014 para funcionamento da UFSB (Pinto et al., 2019).

O município de Porto Seguro possui um clima do tipo Af chuvoso, quente e úmido, sem estação seca definida segundo as definições de Köppen-Geiger (Peel et al., 2007). A temperatura média é de $24^{\circ} \mathrm{C}$, sendo fevereiro o mês mais quente com temperatura média de $26^{\circ} \mathrm{C}$ (INMET, 2019; Climate-data, 2019). A pluviosidade média é de aproximadamente $1.700 \mathrm{~mm}$ (INMET, 2019; Climate-data, 2019). O município está inserido no Domínio da 
Figura 1. Localização do campus Sosígenes Costa (CSC) e do Jardim Botânico FLORAS (JBFLORAS) da Universidade Federal do Sul da Bahia (UFSB), município de Porto Seguro, Bahia, Brasil. Mapa retirado de Pinto et al. (2019). Legenda: A: Mapa do Brasil com destaque para o Es tado da Bahia e o Município de Porto Seguro. B: Campus Sosígenes Costa e o JBFLORAS em destaque (área com delimitação amarela) (Imagem do Google Earth).
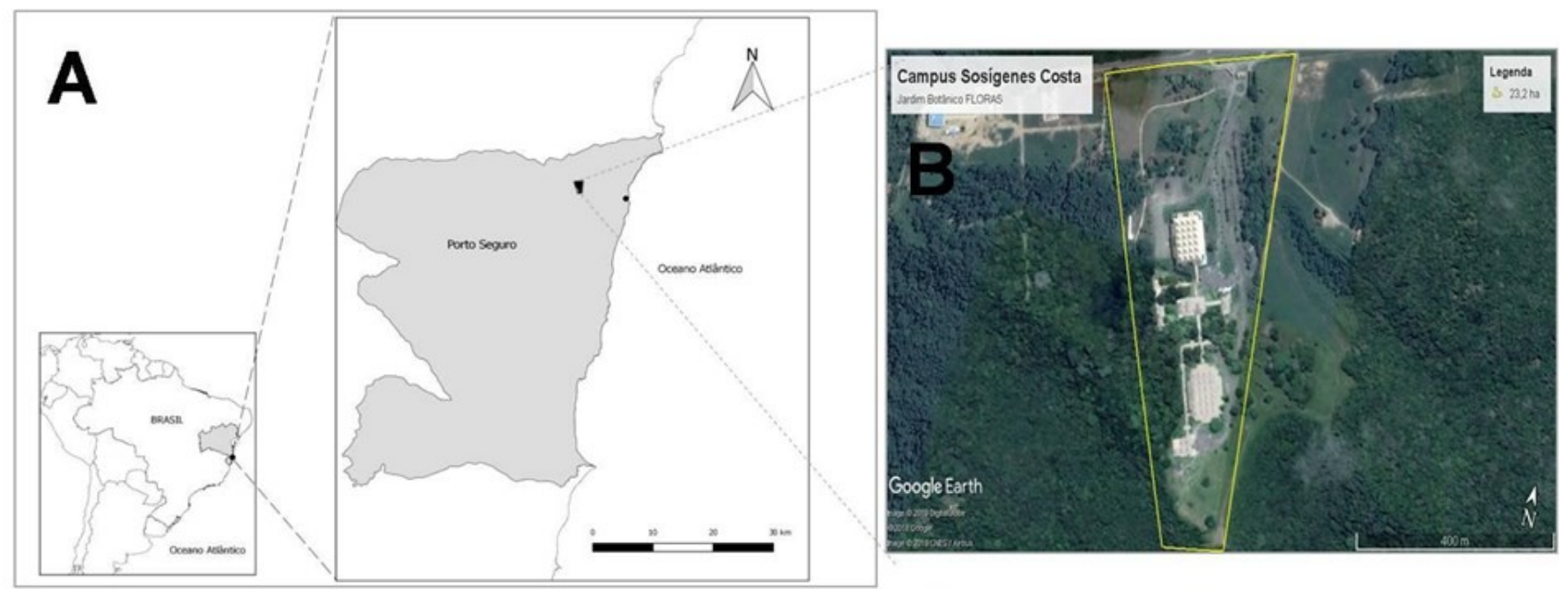

Mata Atlântica, com predominância de florestas e ecossistemas associados como as mussunungas/campinaranas, brejos, várzeas, alagados, restingas e manguezais (IBGE, 2012).

Coleta e análise dos dados

Foram realizadas coletas mensais no período de março/2017 a fevereiro/2018, através de caminhadas pelos canteiros, jardins e espaços administrativos contendo plantas. Nos fragmentos de mata, adotou-se caminhadas em trilhas pré-existentes, seguindo as técnicas usuais de coleta, tratamento, herborização e acondicionamento de material botânico descritas em Fidalgo e Bononi (1989) e IBGE (2012). As identificações foram baseadas na literatura especializada (Alves; Roque, 2016; Barroso et al., 1991a,b, 2001; CarneiroTorres et al., 2017; Gandara et al., 2016; Flora do Brasil, 2020; Lewis, 1987; Lorenzi, 2002a,b, 2009; Oliveira et al., 2016; Ogasawara; Roque, 2015; Lorenzi; Souza, 2015; Souza; Lorenzi, 2019) e na consulta a especialistas, quando necessário. O sistema de classificação das famílias botânicas de angiospermas seguiu o sistema atual de classificação, APG IV (2016). Para as gimnospermas seguiu-se Judd et al. (2009). Os nomes e as sinonímias dos táxons foram verificados no site do IPNI (2020) e no site da Flora do Brasil (2020). Os nomes populares seguiram a indicação dos mateiros que acompanharam algumas coletas e também foram complementados com informação da literatura (Silva et al., 2008; Flora do Brasil, 2020; Lorenzi, 2002a,b, 2009; Lorenzi; Matos, 2008; Lorenzi; Souza, 2015). Todo material coletado encontra-se no Herbário Professor Geraldo C. P. Pinto (GCPP) da Universidade Federal do Sul da Bahia (UFSB) e duplicatas estão sendo enviadas para outros herbários da Bahia e do Brasil, tais como ALCB, BRBA, HUEFS, CEPEC, entre outros - acrônimos de acordo com Thièrs (2020). Para a identificação da origem das espécies foram verificados os sites da Flora do Brasil (2020), GBIF (2020), MOBOT (2020), TROPICOS (2020) e Stevens (2020).

A indicação do potencial ornamental das espécies seguiu um critério subjetivo a partir da observação direta das principais carac- terísticas dos indivíduos existentes no Jardim Botânico. Destacando -se o hábito, a arquitetura e porte da plantas, a coloração e o comprimento das folhas ou ramos e a beleza de suas flores. Para a classificação dos hábitos das plantas foram seguidos Gonçalves e Lorenzi (2011) e Souza et al. (2013), com exceção do grupo das palmeiras que foi considerado como um hábito à parte (Flora do Brasil, 2020). Os ambientes de jardins e canteiros com espécies ornamentais estão distribuídos ao longo do campus (Figuras 1).

\section{Resultados e Discussão}

Foram encontradas 86 espécies de plantas ornamentais distribuídas em 78 gêneros e 39 famílias (Tabela 1). Destas, somente duas espécies pertencem ao grupo das gimnospermas: Cycas revoluta Thunb. e Cycas thouarsii R.Br. (Cycadaceae), ambas conhecidas popularmente como cica.

Diversidade, hábitos e origens das plantas cultivadas no Jardim

As famílias mais diversas foram: Arecaceae e Leguminosae (7\%, N = 6 espécies para cada família); Asparagaceae, Bignoniaceae e Orchidaceae (5,8\%, N = 5 espécies); e Araceae, Bromeliaceae, Myrtaceae e Rubiaceae (4,6\%, N = 4 espécies). A família Leguminosae se destacou dentre as espécies nativas do CSC/JBFLORAS (Pinto et al., 2019) e nos estudos com plantas ornamentais aparece como a família principal (p.ex. Eiseblohr, 2008; Costa et al., 2017; Vichiato; Vichiato, 2017; Moreira; Lopes, 2018) ou entre as cinco mais representativas (p.ex. Leal; Biondi, 2006; Veiga et al., 2009), enquanto Asparagaceae, Arecaceae e Araceae não aparecem entre as dez famílias mais representativas das espécies ornamentais nativas (Veiga et al., 2009), mostrando uma tendência ao uso de espécies exóticas destas famílias botânicas no Brasil.

Os resultados obtidos indicam predominância de espécies exóticas (53,5\% do total amostrado) em relação às nativas (46,5\%). Das seis espécies de Arecaceae cultivadas, apenas duas são nativas 
Tabela 1. Espécies ornamentais cultivadas no campus Sosígenes Costa/Jardim Botânico FLORAS, da Universidade Federal do Sul da Bahia, em Porto Seguro, Bahia, Brasil. EPO: espécies com potencial ornamental ocorrentes na área do fragmento de floresta (Mata Busca Vida).

\begin{tabular}{|c|c|c|c|c|}
\hline Família/espécie & Origem & Hábito & Nome popular & EPO \\
\hline \multicolumn{5}{|l|}{ ACANTHACEAE } \\
\hline Ruellia sp.1 & nativa & herbáceo & & $\mathrm{X}$ \\
\hline Ruellia sp.2 & nativa & herbáceo & & $\mathrm{X}$ \\
\hline \multicolumn{5}{|l|}{ AMARANTHACEAE } \\
\hline $\begin{array}{l}\text { Alternanthera littoralis var. maritima (Mart.) } \\
\text { Pedersen }\end{array}$ & nativa & herbáceo & penicilina & \\
\hline \multicolumn{5}{|l|}{ AMARYLLIDACEAE } \\
\hline Hymenocallis littoralis (Jacq.) Salisb & nativa & herbáceo & lírio-aranha & \\
\hline \multicolumn{5}{|l|}{ ASPARAGACEAE } \\
\hline Agave americana $\mathrm{L}$. & exótica & arbustivo & piteira-azul, agave & \\
\hline Agave angustifolia Haw. & exótica & herbáceo & piteira, agave & \\
\hline Cordyline fruticosa (L.) A. Chev. & exótica & arbustivo & dracena-vermelha & \\
\hline Dracaena marginata Lam. & exótica & arbustivo & dracena-de-madagascar & \\
\hline Sanservieria trifasciata Prain & exótica & herbáceo & espada-de-são-jorge & \\
\hline \multicolumn{5}{|l|}{ ASTERACEAE } \\
\hline Sphagneticola trilobata (L.) Pruski & nativa & herbáceo & bem-me-quer & $\mathrm{X}$ \\
\hline \multicolumn{5}{|l|}{ ANACARDIACEAE } \\
\hline Mangifera indica $\mathrm{L}$. & exótica & Arbóreo & Mangueira & \\
\hline Schinus terebinthifolia Raddi & nativa & Arbóreo & Aroeira & \\
\hline \multicolumn{5}{|l|}{ APOCYNACEAE } \\
\hline Catharanthus roseus (L.) G. Don & exótica & arbustivo & vinca & \\
\hline Plumeria rubra L. & exótica & arbustivo & jasmim-manga & \\
\hline \multicolumn{5}{|l|}{ ARACEAE } \\
\hline Dieffenbachia amoena Bull. & exótica & herbáceo & comigo-ninguém-pode & \\
\hline Monstera $\mathrm{cf}$. adansonii Schott & nativa & trepador/liana & costela-de-adão & \\
\hline Philodendron imbe Schott ex Kunth & nativa & trepador/liana & tracoá; folha-de- fonte & \\
\hline Spathiphyllum wallisii Regel & exótica & herbáceo & lírio-da-paz & \\
\hline \multicolumn{5}{|l|}{ ARALIACEAE } \\
\hline Schefflera arboricola (Hayata) Merr. & exótica & arbustivo & cheflera-pequena & \\
\hline \multicolumn{5}{|l|}{ ARECACEAE } \\
\hline Cocos nucifera $\mathrm{L}$. & exótica & palmeira & coqueiro-anão & \\
\hline Elaeis cf. guineenses (Kunth) Cortés & exótica & palmeira & dendê & \\
\hline Euterpe oleracea Mart. & nativa & palmeira & açaí & \\
\hline Licuala cf. grandis H.Wendl. ex Linden & exótica & palmeira & palmeira-leque & \\
\hline Roystonea oleracea (Jacq.) O. F. Cook & exótica & palmeira & palmeira-imperial & \\
\hline Veitchia merrillii (Becc.) H.E.Moore & exótica & palmeira & palmeira-de-manila & \\
\hline \multicolumn{5}{|l|}{ BIGNONIACEAE } \\
\hline Crescentia cujete $\mathrm{L}$. & exótica & Arbóreo & coité & \\
\hline Fredericia pubescens (L.) L.G. Lohmann & nativa & trepador/liana & & $\mathrm{X}$ \\
\hline Handroanthus heptaphyllus (Mart) Mattos & nativa & Arbóreo & ipê-roxo & \\
\hline Handroanthus sp. & nativa & Arbóreo & ipê & \\
\hline Lundia longa (Vell.) DC. & nativa & trepador/liana & & $\mathrm{X}$ \\
\hline \multicolumn{5}{|l|}{ BROMELIACEAE } \\
\hline Hohenbergia sp. & nativa & herbáceo & bromélia & \\
\hline Tillandsia gardnerii Lindl. & nativa & herbáceo & & \\
\hline Tillandsia stricto Sol. ex KerGawl & nativa & herbáceo & & \\
\hline Vriesia procera Mez & nativa & herbáceo & bromélia & \\
\hline \multicolumn{5}{|l|}{ CANNACEAE } \\
\hline Canna paniculata Ruiz \& Pav. & nativa & herbáceo & beri, cana-da-índia, caité-do-brejo & \\
\hline \multicolumn{5}{|l|}{ COMMELINACEAE } \\
\hline Dichorisandra sp. & nativa & herbáceo & & $\mathrm{X}$ \\
\hline CLUSIACEAE & & & & \\
\hline Clusia fluminensis Planch. \&Triana & nativa & arbustivo & clusia & \\
\hline CYCADACEAE & & & & \\
\hline Cycas revoluta Thunb. & exótica & arbustivo & cica & \\
\hline Cycas thouarsii R.Br. ex Gaudich. & exótica & arbustivo & cica & \\
\hline EUPHORBIACEAE & & & & \\
\hline Jatropha gossypiifolia L. & nativa & arbustivo & pinhão-roxo & \\
\hline HELICONIACEAE & & & & \\
\hline Heliconia richardiana Miq. & nativa & herbáceo & & $\mathrm{X}$ \\
\hline LAMIACEAE & & & & \\
\hline Clerodendrum $x$ speciosum Tiejism. \& Binn & exótica & arbustivo & coração-sangrento & \\
\hline Congea tomentosa Roxb. & exótica & trepador/liana & congeia & \\
\hline LECYTHIDACEAE & & & & \\
\hline Eschweilera ovata (Cambess.) Mart. ex Miers & nativa & Arbóreo & biriba & \\
\hline
\end{tabular}


Tabela 1. Continuação.

\begin{tabular}{|c|c|c|c|c|}
\hline Família/espécie & Origem & Hábito & Nome popular & EPO \\
\hline \multicolumn{5}{|l|}{ LEGUMINOSAE } \\
\hline \multirow{5}{*}{$\begin{array}{l}\text { Caesalpinia pulcherrima (L.) Sw. } \\
\text { Dalbergia nigra (Vell.) Allemão ex Benth. } \\
\text { Paubrasilia echinata (Lam.) Gagnon, } \\
\text { H.C.Lima \& G.P.Lewis } \\
\text { Peltophorum dubium (Spreng) Taub. } \\
\text { Senna macranthera (Collad.) Irwin \& Barneby } \\
\text { var. macranthera }\end{array}$} & exótica & arbustivo & Flamboianzinho & \\
\hline & nativa & Arbóreo & Jacarandá & $\mathrm{X}$ \\
\hline & nativa & Arbóreo & pau-brasil, ibirapitanga, ibirapiranga & \\
\hline & nativa & Arbóreo & ibirá-pitá, canafístula, sobrasil & \\
\hline & nativa & Arbóreo & são-joão, acássia & \\
\hline Senna spectabilis (DC.) Irwin \& Barneby & nativa & Arbóreo & $\begin{array}{l}\text { canafístula, cássia, cássia-do- } \\
\text { nordeste }\end{array}$ & \\
\hline \multicolumn{5}{|l|}{ LYTHRACEAE } \\
\hline Lagerstroemia indica $\mathrm{L}$. & exótica & arbustivo & extremosa, reseda & \\
\hline \multicolumn{5}{|l|}{ MALPIGHIACEAE } \\
\hline Byrsonima sericea DC. & nativa & Arbóreo & murici & \\
\hline Malpighia emarginata Sessé \& Moc. ex DC. & exótica & Arbóreo & acerola & \\
\hline \multicolumn{5}{|l|}{ MALVACEAE } \\
\hline Hibiscus rosa-sinensis $\mathrm{L}$. & exótica & arbustivo & hibisco & \\
\hline Bombax ceiba $\mathrm{L}$ & exótica & Arbóreo & paineira-vermelha-da-índia & \\
\hline Theobroma cacao L. & exótica & Arbóreo & cacau & \\
\hline \multicolumn{5}{|l|}{ MARANTACEAE } \\
\hline Stromanthe schottiana (Korn.) Eichler & nativa & herbáceo & & $\mathrm{X}$ \\
\hline \multicolumn{5}{|l|}{ MELASTOMATACEAE } \\
\hline Miconia albicans (Sw.) Triana & nativa & arbustivo & canela-de-velho & \\
\hline \multicolumn{5}{|l|}{ MORACEAE } \\
\hline Artocarpus beterophyllus Lam. & exótica & Arbóreo & jaqueira & \\
\hline & exótica & Arbóreo & ficus & \\
\hline \multicolumn{5}{|l|}{ MUSACEAE } \\
\hline Musa $x$ paradisiaca L. & exótica & herbáceo & bananeira & \\
\hline \multicolumn{5}{|l|}{ MYRTACEAE } \\
\hline Eugenia uniflora L. & nativa & Arbóreo & pitanga & \\
\hline Psidium guajava L. & exótica & Arbóreo & goiaba, araçá-goiaba & \\
\hline Syzygium cumini (L.) Skeels & exótica & Arbóreo & jamelão, jambolão & \\
\hline Syzygium $\mathrm{cf}$. malaccense $\mathrm{L}$. & exótica & Arbóreo & jambo & \\
\hline \multicolumn{5}{|l|}{ ORCHIDACEAE } \\
\hline Catasetum purum Nees \& Sinning & nativa & herbáceo & Orquídea & \\
\hline Eltroplectris calcarata (Sw.) Garray \& Swet & nativa & herbáceo & Orquídea-bigode & \\
\hline Epidendrum sp. & nativa & herbáceo & Orquídea & \\
\hline Polystachia estrellensis (Jacq.) Garray \& Swet & nativa & herbáceo & Orquídea & \\
\hline Sacoila lanceolata (Aubl.) Garray & nativa & herbáceo & Orquídea & \\
\hline \multicolumn{5}{|l|}{ POACEAE } \\
\hline Cymbopogon winterianus Jowitt ex Bor & exótica & herbáceo & citronela & \\
\hline Bambusa vulgaris Schrad. ex J.C. Wendl. & exótica & herbáceo & bambu & \\
\hline \multicolumn{5}{|l|}{ RUBIACEAE } \\
\hline Genipa americana $\mathrm{L}$. & nativa & Arbóreo & jenipapo & \\
\hline Ixora chinensis Lam. & exótica & arbustivo & & \\
\hline Ixora coccinea $\mathrm{L}$. & exótica & arbustivo & ixora, ixora-coral & \\
\hline Morinda citrifolia $\mathrm{L}$. & exótica & Arbóreo & noni & \\
\hline \multicolumn{5}{|l|}{ RUTACEAE } \\
\hline Citrus reticulata Blanco & exótica & Arbóreo & tangerina, mexerica & \\
\hline \multicolumn{5}{|l|}{ SCROPHULARIACEAE } \\
\hline Russelia equisetiformis Schlecht. \& Cham. & exótica & herbáceo & Flor-de-coral & \\
\hline SOLANACEAE & & & & \\
\hline Capsicum frutescens $\mathrm{L}$. & exótica & arbustivo & pimenta-malagueta & \\
\hline Solandra grandiflora Sw. & nativa & trepador/liana & solandra & \\
\hline STRELITZIACEAE & & & & \\
\hline Ravenala madagascariensis Sonn. & exótica & herbáceo & árvore-do-viajante & \\
\hline Strelitzia reginae Aiton & exótica & herbáceo & flor-ave-do-paraíso & \\
\hline URTICACEAE & & & & \\
\hline Cecropia pachystachya Trécul & nativa & Arbóreo & embaúba & \\
\hline Urera baccifera (L.) Gaudick. ex Wedd. & nativa & arbustivo & urtiga-brava & $\mathrm{X}$ \\
\hline VERBENACEAE & & & & \\
\hline Duranta erecta L. & exótica & arbustivo & pingo-de-ouro & \\
\hline ZINGIBERACEAE & & & & \\
\hline Alpinia purpurata K.Schum. & exótica & herbáceo & alpínia & \\
\hline
\end{tabular}


do Brasil. A predominância de espécies de Arecaceae exóticas foi também identificada por Lombardi e Morais (2003) e Eisenlohr (2008), apesar de existir uma grande diversidade de espécies nativas desta família com potencial ornamental (Medeiros-Costa, 2003). Em relação à segunda família mais abundante, Asparagaceae, todas as cinco espécies são exóticas.

As espécies com maior número de indivíduos plantados nas áreas do campus são exóticas, com destaque para Ixora coccinea, I. chinensis (Rubiaceae), Cycas thouarsii (Cycadaceae), Psidium guajava (Myrtaceae) e Veitchia merrillii (Arecaceae). Essa utilização predominante de espécies exóticas no campus indica forte ligação com a história do paisagismo no Brasil, em que as espécies cultivadas nos jardins eram trazidas de outros países e estas representavam a riqueza dos proprietários (Delphim, 2005). Além disso, o cultivo de espécies ornamentais exóticas é praticamente compulsório, uma vez que ainda é reduzida a oferta de espécies ornamentais nativas, e não é raro que, inseridas em um comércio já bem estabelecido, determinadas espécies estejam selecionadas para melhor adaptação e menores cuidados de manutenção (Figura 2). Ademais, possuem a vantagem de nem sempre encontrar predadores ou patógenos em seu novo local de cultivo (Leal; Biondi, 2006).

O hábito predominante foi o herbáceo (33,7\%, N = 29 spp.), seguido pelo arbóreo $(29,13 \%, \mathrm{~N}=25 \mathrm{spp}$.), arbustivo (23,3\%, N =20 spp.), trepadeira/liana e palmeiras (6,97\%, N = 6 spp. em cada hábito). As espécies herbáceas são geralmente predominantes entre as ornamentais por apresentarem facilidade no cultivo e pela menor duração do seu ciclo reprodutivo (Leal; Biondi, 2006; Vichiato; Vichiato, 2017).

A preferência pelo cultivo de angiospermas reflete o interesse no uso das flores e frutos na ornamentação, contudo, entre as espécies com maior frequência de cultivo no campus, apenas as ixoras (I. coccinea e I. chinensis) possuem floração constante, favorecendo seu uso em vários jardins do campus. No entanto, a busca por alternativas como a cássia-do-nordeste (Senna spectabilis), o lírio-aranha (Hymenocallis littoralis) ou outras espécies nativas pode ajudar na sustentabilidade da área à medida que mantém a beleza cênica e permite o equilíbrio ecológico com a atração da fauna nativa, por exemplo.

A presença frequente de espécies frutíferas nas áreas de jardins do campus, como Psidium guajava (goiabeira), Musa paradisiaca (bananeira), Eugenia uniflora (pitangueira), Malpighia emarginata (aceroleira), Artocarpus beterophyllus (jaqueira), Sysygium malaccense (jameleiro), Cocos nucifera (coqueiro), Citrus reticulata (tangerineira), entre outras (Tabela 1), remonta ao costume tipicamente português de associar o jardim à horta e ao pomar (Delphim, 2005). Considera-se também que tal característica deva-se ao fato de a área do campus Sosígenes Costa, antes de ser inaugurado como Centro de Convenções de Porto Seguro no ano 2000, ter sido área de fazenda com cultivo principalmente de cacau. Espécies recomendadas para o Nordeste podem ajudar a incrementar as frutíferas do campus/ JBFLORAS com frutíferas nativas que agreguem múltiplos usos (Coradin et al., 2018; Pinto et al., 2019).

O número de espécies ornamentais entre os canteiros, bosques e jardins internos varia entre quatro e 20 espécies. Em algumas áreas de jardim há predominância visível de determinadas espécies, tais como como o renque de palmeiras-imperiais (Roystonea oleracea), o renque de fícus (Ficus benjamina), o bosque de árvores-do-viajante (Ravenala madagascariensis), todas elas distribuídas isoladamente na entrada do campus (Figura 3). Nas demais áreas do campus não foi possível identificar uma padronização clara entre as plantas cultivadas nos jardins do CSC/Jardim Botânico FLORAS, mas observa-se uma tendência à homogeneização dos plantios entre estas áreas, geralmente com espécies ornamentais exóticas amplamente comercializadas. A distribuição homogênea de espécies em uma área pode favorecer a propagação de pragas, podendo levar à perda dos indivíduos daquela espécie e a altos custos operacionais (Rodolfo Júnior et al., 2008). Assim, recomenda-se que este fator seja considerado em manejos futuros nas áreas de cultivo ornamental do campus.

Carvalho et al. (2013) destacaram os riscos da utilização de Ficus benjamina (fícus) na arborização urbana, uma vez que esta planta possui sistema radicular agressivo e crescimento rápido, implicando na degradação de pavimentos e fiações, sendo indicado apenas para espaços sem nenhuma pavimentação (Miranda et al., 2012; Rodolfo Júnior et al., 2008). Não foram identificados outros problemas quanto à ornamentação do campus/JBFLORAS em relação ao risco de destruição de vias e calçadas.

A diversidade de espécies no campus/JBFLORAS, apesar de proporcionar beleza cênica, não parece contribuir para a ambientação visual de uma identidade regional, principalmente devido ao maior emprego de espécies exóticas (Tabela 1).

Esse uso preferencial de espécies exóticas parece ser proveniente de um manejo mais recente no local do que aquelas inicialmente plantadas no Centro de Convenções no ano 2000 realizada pelos paisagistas. Ao se observar os jardins principais junto aos prédios antigos do local, existe uma tendência ao uso de espécies da flora nativa de diferentes biomas brasileiros, tais como a Caatinga, o Cerrado e a própria Mata Atlântica. As plantas nativas encontradas e as disposições nos jardins e canteiros parecem ser remanescentes de um paisagismo que ressaltava a história e a diversidade ambiental brasileira. Essa suspeita foi reforçada pelas conversas informais realizadas com antigos trabalhadores do local que lembraram existir outros arranjos de plantas, onde atualmente predominam ixoras, coqueiros e cicas.

\section{Espécies ornamentais nativas}

Das 40 espécies ornamentais nativas que integram a composição dos jardins e canteiros, destacam-se plantas de relevante beleza cênica (Figura 4), como a Solandra grandiflora, trepadeira ramificada, nativa da Mata Atlântica, cujas flores chamam a atenção por serem grandes, em forma de trombeta, amarelo-ocre, com aroma suave mais acentuado a noite, indicando polinização por morcegos (Soares; Quental, 2016). Segundo Lorenzi e Souza (2015), esta é uma planta ainda rara em cultivo com grande potencial ornamental.

O ipê-roxo (Handroanthus heptaphyllus), quando em época de floração também apresenta volumosas inflorescências arroxeadas que atraem visitantes florais. A árvore Senna macranthera (são-joão), no período de floração, emite grande quantidade de flores amarelas, atraindo muitas abelhas vibradoras. Outra árvore com abundante floração e flores amarelas é o ibirá-pitá (Peltrophorum dubium) que proporciona grande oferta de recursos para as abelhas (Figura 4). Esta espécie é mais conhecida como "canafístula" (Matos; Queiroz, 2009), apesar de ser um nome popular atribuído a diferentes espécies de Senna (p.ex. Costa et al., 2002; Queiroz, 2009). Peltrophorum dubium apresenta amplitude de usos, tendo praticamente todas as 
Figura 2. Flores de espécies ornamentais exóticas entre as zonas de jardim do campus Sosígenes Costa. A: Bombax ceiba; B: Spathiphyllum wallisii; C: Lagerstroemia indica; D: Plumeria rubra. Fotos: Tainá Antunes.

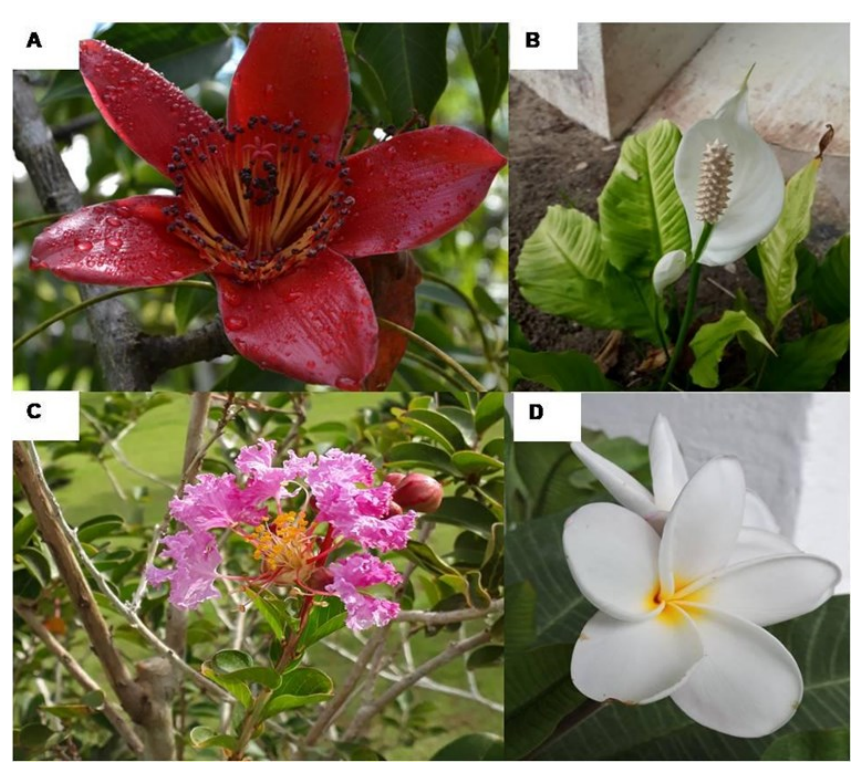

Figura 3. Ambientes do Jardim Botânico FLORAS. A: Entrada do campus com indivíduos de Roystonea oleracea, B: Jardim com Ixora coccinea; C: Jardim do prédio administrativo com predomínio de Cordyline fruticosa; D: Jardim de Ravenala madagascariensis; E: Área de borda do fragmento de Mata Attântica. Fotos: Jorge Costa.

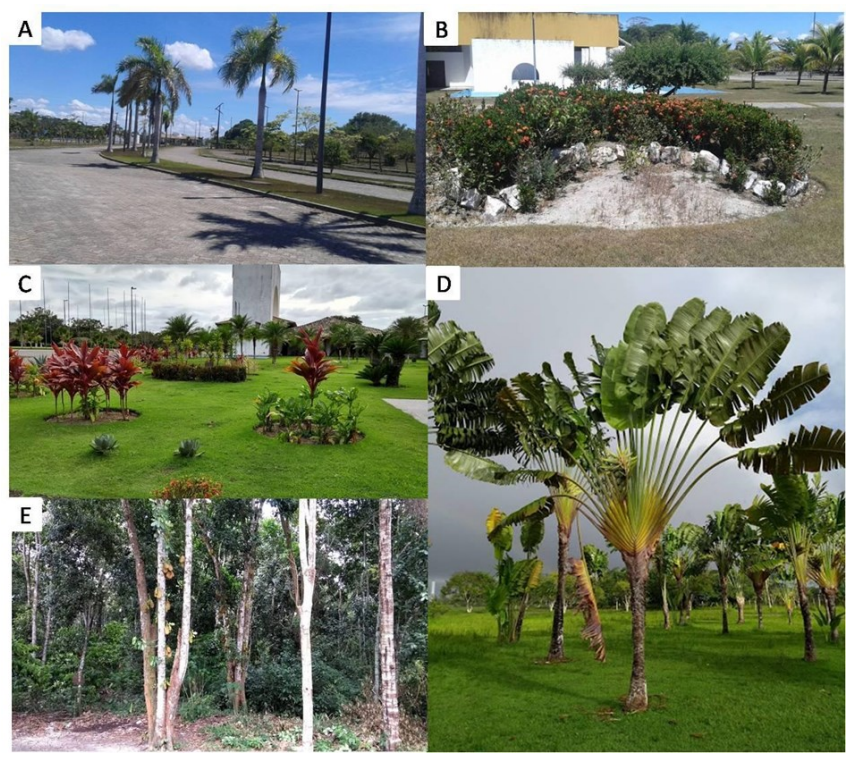

Figura 4. Espécies nativas ornamentais do Jardim Botânico FLORAS. A: Eugenia uniflora; B: Solandra grandiflora; C: Peltophorum dubium; D-E: Senna macranthera; F:Eschweilera ovata; G: Fridericia pubescens; H: Heliconia richardiana; I: Dalbergia nigra. Fotos: Tainá Antunes

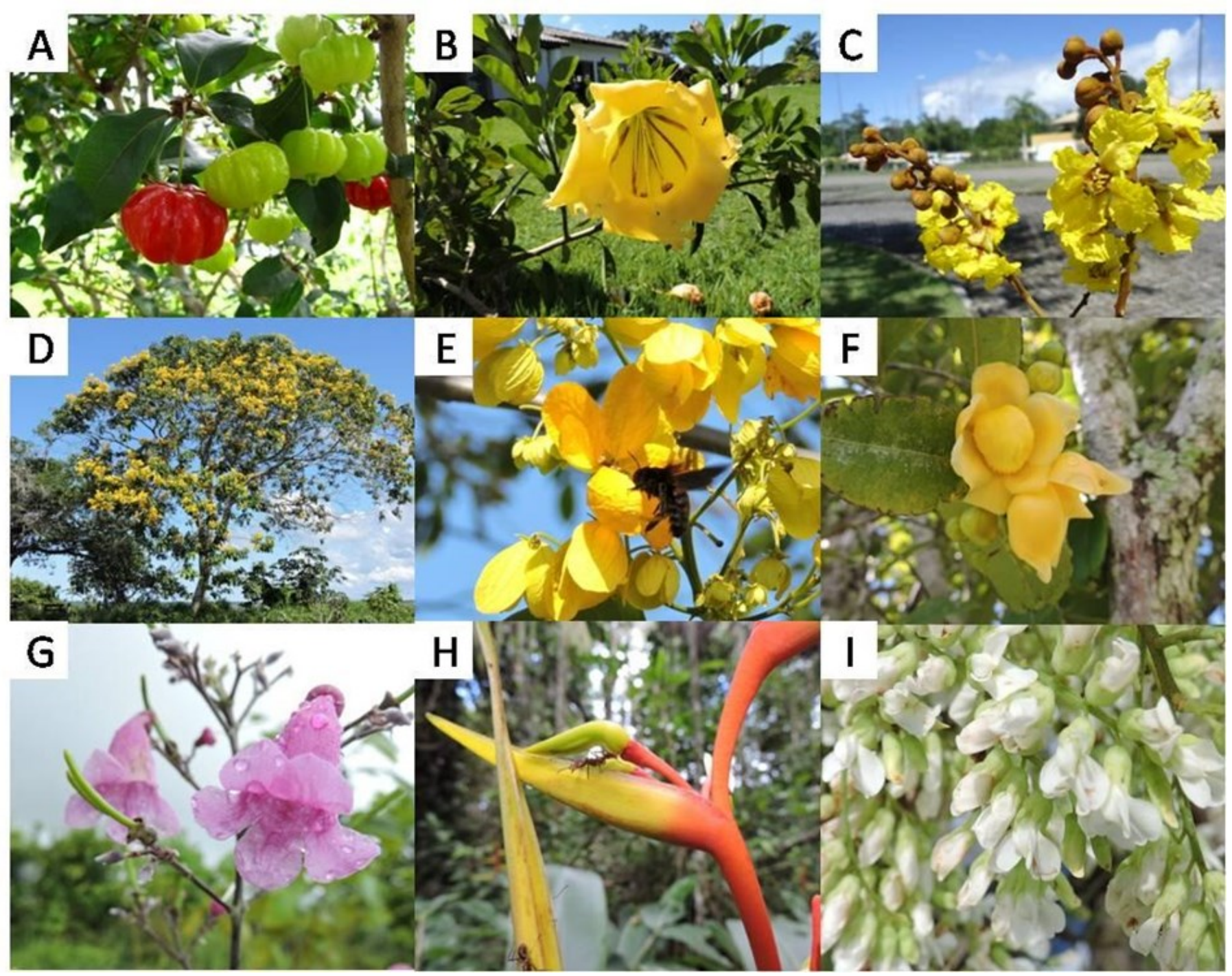


suas partes aproveitadas como medicinal e na construção civil (Matos; Queiroz, 2009). Seu uso como corante foi responsável por seu nome popular, pois os índios Tupi a denominam ibirá-pitá devido à madeira vermelha que possui (Soares; Quental, 2016). Outras espécies nativas com múltiplos usos e valores culturais podem ser introduzidas no JBFLORAS tendo como base as informações contidas na iniciativa "Plantas para o Futuro" do Ministério do Meio Ambiente (Coradin et al., 2011; Vieira et al., 2016; Coradin et al., 2018) e outras bases (p.ex. Flora do Brasil 2020).

Há também aquelas espécies cujas folhagens são a principal característica ornamental, como a arbustiva Clusia fluminensis, endêmica da Mata Atlântica brasileira, que apresenta folhas rígidas, lisas e brilhantes. No campus Sosígenes Costa, está restrita a poucos indivíduos, mas como espécie bem adaptada ao litoral (Lorenzi; Souza, 2015), pode ser melhor aproveitada no paisagismo.

Outras duas espécies nativas e endêmicas do Brasil merecem destaque por terem seus usos atrelados à história do Brasil: a biriba (Eschweilera ovata) e o pau-brasil (Paubrasilia echinata). A biriba foi muito utilizada na construção do berimbau, instrumento essencial tocado nas rodas de capoeira. Já o pau-brasil possui um histórico de mais de 500 anos de exploração e rendeu aos colonizadores muito dinheiro (D’Agustini et al., 2013). Era utilizada como tintura para tecido e sua madeira (atualmente de exploração proibida) é ainda cobiçada para a construção de violinos, processo que levou o paubrasil a integrar a lista de espécies em risco de extinção (Martinelli; Moraes, 2013). O desenvolvimento de tecnologias de manejo dessas espécies é recomendado.

\section{Espécies nativas com potencial ornamental ocorrentes na Mata Busca Vida}

Foram levantadas 10 espécies de plantas nativas com potencial ornamental presentes no fragmento de Mata Atlântica do JBFLORAS (Tabela 1). As características utilizadas para a identificação de potencial ornamental foram: 1) as flores vistosas, delicadas e coloridas como as de Fridericia pubescens, Lundia longa, Dichorisandra thysiflora, Ruellia spp., Sphagneticola trilobata; 2) as flores abundantes e muito perfumadas como as do jacarandá (Dalbergia nigra); 3) os frutos com arranjo diferenciado (p.ex. Urera bacifera); 4) as brácteas coloridas e chamativas como as encontradas em Heliconia richardiana e Stromanthe schottiana. Além disso, Fridericia pubescens e Lundia longa apresentam potencial como cerca-viva por seus hábitos de liana e suas folhas grandes e brilhantes.

Apesar de não serem utilizadas como ornamentais no campus, algumas espécies possuem usos já registrados em outros locais, tais como Sphagneticola trilobata (Lemões et al., 2012) e Heliconia richardiana (Lorenzi; Souza, 2015), o que reforça a ideia de aproveitamento das espécies nativas locais para diversificação e adequação do paisagismo.

Trabalhos como os de Tognon e Cuquel (2016), Heiden et al. (2006, 2007), Martini et al. (2010), Leal e Biondi (2006) e Machado et al. (2006), que realizaram prospecções de espécies nativas com potencial ornamental, destacaram a viabilidade do cultivo de espécies nativas de diversos hábitos, principalmente arbóreas, para compor a arborização de cidades, jardins urbanos e outras áreas verdes como alternativas às exóticas amplamente cultivadas. O cultivo de espécies nativas com potencial econômico vai além das plantas ornamentais, mas a associação de características ornamentais aos aspectos agrícola, ecológico, genético, social, econômico, científico, educacional, cultural, recreativo e estético permite a conservação e valorização da biodiversidade brasileira (Coradin et al., 2011; BFG, 2015; Vieira et al., 2018; Coradin et al., 2018), além de integrar essas áreas na paisagem regional de forma a garantir uma maior harmonização ambiental na matriz urbano-rural das cidades brasileiras.

A conservação ex situ de espécies nativas em Jardins Botânicos e o desenvolvimento de tecnologias de reintrodução na natureza é uma das metas da Estratégia Global para a Conservação de Plantas (sigla em inglês GSPC), tornando os jardins botânicos de grande relevância para a conservação da biodiversidade (GSPC, 2012; BFG, 2018). Atualmente, cerca de um terço das plantas conhecidas está em jardins botânicos de todo o mundo (Mounce et al., 2017), o que mostra a importância de se avançar em estudos locais que ampliem o conhecimento sobre as espécies nativas e sua conservação. Assim, espera-se que o Jardim Botânico FLORAS possa contribuir tanto com a conservação ex situ das espécies nativas ornamentais ou com potencial ornamental como também ajudar na valorização destas plantas e de suas características associadas.

\section{Conclusão}

Neste estudo, verificou-se a tendência ao cultivo de espécies ornamentais exóticas entre os jardins e canteiros do Campus Sosígenes Costa/Jardim Botânico FLORAS, enquanto a existência de plantas nativas potencialmente interessantes do ponto de vista paisagístico, ecológico e histórico, revelou-se predominante no fragmento da Mata Busca Vida.

Sugere-se a ampliação do cultivo de Paubrasilia echinata, visto a importância histórica desta espécie, seu endemismo e risco de extinção; incremento das áreas de jardins, a partir de estudos e de planejamentos prévios, no sentido de aumentar a variabilidade genética conservada no JBFLORAS. No intuito de incrementar a biodiversidade vegetal nos jardins do CSC, recomenda-se o uso de espécies nativas oriundas dos domínios fitogeográficos brasileiros, especialmente da Mata Atlântica do Sul da Bahia, visando o desenvolvimento de tecnologias, a conservação ex situ e a valorização destas plantas a partir da disseminação dos conhecimentos relativos às mesmas.

O cultivo de plantas nativas com potencial ornamental como Solandra grandiflora, Fridericia pubescens, Lundia longa, entre outras indicadas no presente estudo e de espécies ocorrentes na região sul da Bahia ainda não cultivadas no campus também é recomentado.

\section{Agradecimentos}

Os autores agradecem aos senhores Matias dos Santos Santana, "Bira" (Florisvaldo Climério Santana), Oziel Almeida Santos, Roberto Farias Souza e "Inho" (Elinoildo Brito Santos), pelos auxílios em campo e com nomes comuns das plantas. À UFSB, representada pelos funcionários do setor administrativo do campus Sosígenes Costa, por todo o apoio e incentivo.

\section{Financiamento}

Os autores declaram não haver fontes de financiamento a informar. 


\section{Contribuições de autoria}

Conceitualização: JASC, CBNC, TJA. Curadoria de dados: TJA, JASC, CBNC, VCS. Análise formal: JASC, CBNC. Aquisição de financiamento: não se aplica. Investigação: TJA, JASC, CBNC. Metodologia: TJA, JASC, CBNC, VCS. Administração do projeto: TJA, JASC, CBNC. Recursos: TJA, JASC, CBNC. Programas: TJA. Supervisão: JASC. Validação: JASC, CBNC. Visualização: TJA, JASC, CBNC. Redação - rascunho original: TJA, CBNC, JASC. Redação - revisão e edição: JASC, CBNC.

\section{Conflito de interesses}

Os autores declaram não haver conflitos de interesse a informar.

\section{Disponibilidade dos dados}

Os dados integrais analisados durante o estudo atual estão apresentados no corpo do manuscrito.

\section{Conformidade ética}

.Não se aplica.

\section{Referências}

Almeida EA, Carneiro ARS, Alves MV. Aspectos da história dos jardins botânicos no mundo e no brasil - uma abordagem sobre o jardim botânico do Recife-PE. Paisagem e Ambiente 1999;12:9-28. doi: 10.11606/issn.2359-5361.v0i12p9-28

APG IV. An update of the Angiosperm Phylogeny Group classification for the orders and families of flowering plants: APG IV. Botanical Journal of the Linnean Society 2016;181(1):1-20. doi: $\underline{10.1111 / \text { boj. } 12385}$

Barroso GM, Peixoto AL, Costa CG, Ichaso CLF, Guimarães EF, Lima HC. Sistemática de angiospermas do Brasil. v. 2. Viçosa: UFV; 1991a.

Barroso GM, Peixoto AL, Costa CG, Ichaso CLF, Guimarães EF, Lima HC. Sistemática de angiospermas do Brasil. v. 3. Viçosa: UFV; $1991 \mathrm{~b}$.

Barroso GM, Morim MP, Peixoto AL, Ichaso CLF. Sistemática de angiospermas do Brasil. v. 1. 2. ed. Rio de Janeiro: LTC; São Paulo: Edusp; 2001

BFG-Brazilian Flora Group. Growing knowledge: an overview of Seed Plant diversity in Brazil. Rodriguésia 2015;66(4):1-29. doi: 10.1590/2175-7860201566411

BFG-Brazilian Flora Group. Brazilian Flora 2020: Innovation and collaboration to meet Target 1 of the Global Strategy for Plant Conservation (GSPC). Rodriguésia 2018;69(4):1513-1527. doi: 10.1590/2175-7860201869402

Buckstrup M, Bassuk N. Native vs. exotic for the home landscape. Ecogardening Factsheet, Cornell University 1997;18.

Carneiro-Torres DS, Silva OLM, Cordeiro I. Flora da Bahia: Euphorbia (Euphorbiaceae). Sitientibus série Ciências Biológicas 2017;17. doi: $10.13102 / \mathrm{scb} 2676$

Climate-data [Internet]. Porto Seguro. [acesso em 29 abr 2019]. Disponível em: https://pt.climate-data.org/search/? $q=$ Porto + Seguro

Coradin L, Camillo J, Pareyn FGC. Espécies nativas da flora brasileira de valor econômico atual ou potencial: plantas para o futuro: região Nordeste [recurso eletrônico]. Série Biodiversidade
51. Brasília/DF: Ministério do Meio Ambiente/Secretaria de Biodiversidade; 2018.1311p. Disponível em: http:// www.mma.gov.br/publicacoes/biodiversidade/category/142serie-biodiversidade/

Coradin L, Siminski A, Reis A. Espécies nativas da flora brasileira de valor econômico atual ou potencial: plantas para o futuro Região Sul. Série Biodiversidade 40. Brasília: Ministério do Meio Ambiente; 2011. Disponível em: https://www.mma.gov.br/ publicacoes/biodiversidade/category/142-seriebiodiversidade.html

Costa JAS, Nunes TS, Ferreira APL, Stradmann MTS, Queiroz LP. Leguminosas forrageiras da Caatinga: espécies importantes para as comunidades rurais do sertão da Bahia. Feira de Santana: Universidade Estadual de Feira de Santana, SASOP; 2002.

Costa LBS, Pires, CS, Anjos, JS, Correia BEF, Almeida Jr. EB. Floristic survey of ornamental plants used in Dom Delgado University City at the Universidade Federal do Maranhão, São Luís, Maranhão State, Brazil. Ornamental Horticulture 2017; 23 (4):451-459. doi: 10.14295/oh.v23i4.1129

Carvalho AA, Da Silva LF, De Lima AP; Santos, TP. A inviabiliadade do ficus (Ficus benjamina L.) para arborização viária. XIII Jornada De Ensino, Pesquisa E Extensão - JEPEX 2013 - UFRPE: Recife; 2013.

Delphim CFM. Intervenções em jardins históricos: manual. Brasília: IPHAN; 2005.

Dourado GM. Modernidade verde: jardins de Burle Marx. São Paulo: Senac; 2009.

Eisenlohr PV, De Carvalho-Okano RM, Vieira MF, Leone FR, Stringheta ÂCO. Flora fanerogâmica do campus da Universidade Federal de Viçosa, Viçosa, Minas Gerais. Revista Ceres 2008,55 (4):317-326.

Felippe G, Zaidan LP. Do Éden ao Éden: jardins botânicos e a aventura das plantas. São Paulo: Editora Senac; 2008.

Fidalgo O, Bononi VLR (coords.). Técnicas de coleta, preservação e herborização de material botânico. São Paulo: Instituto de Botânica; 1989.

Gandara A, Alves M, Roque N. Flora da Bahia: Asteraceae - Tribo Millerieae. Sitientibus série Ciências Biológicas 2016;16. doi: $10.13102 / \mathrm{scb} 844$

GBIF-Global Biodiversity Information Facility. [internet]. [acesso em 7 jul 2020]. Disponível em: https://www.gbif.org/dataset/ search

GSPC-Guide Strategy for Plant Conservation (2011-2020). Plants 2020; 2012. [acesso em 7 jul 2020]. Disponível em: http:// www.plants2020.net/files/Plants2020/popular guide/ englishguide.pdf

Gonçalves EG, Lorenzi H. Morfologia vegetal: organografia e dicionário ilustrado de morfologia das plantas vasculares. 2. ed. São Paulo: Instituto Plantarum de Estudos da Flora; 2011.

Heiden G, Barbieri RL, Stumpf ERT. Considerações sobre o uso de plantas ornamentais nativas. Revista Brasileira de Horticultura Ornamental 2006;12(1):2-7.

Heiden G, Stumpf ET, Barbieri RL, Grolli PR. Uso de plantas arbóreas e arbustivas nativas do Rio Grande do Sul como alternativa a ornamentais exóticas. Revista Brasileira de Agroecologia 2007;2(1).

IBGE-Instituto Brasileiro de Geografia e Estatística. Manual técnico da vegetação brasileira. 2. ed. rev. e ampl. Rio de Janeiro: IBGE; 2012.

INMET-Instituto Nacional de Meteorologia [Internet]. Temperaturas médias observadas - válidas para 2018. [acesso em 29 abr 2019]. Disponível em: http://www.inmet.gov.br/portal/ index.php? $\mathrm{r}=\mathrm{clima} /$ page\&page $=$ anomaliaTempMediaAnual

IPNI-International Plant Names Index [Internet]. The Royal Botanic Gardens, Kew, Harvard University Herbaria \& Libraries and Australian National Botanic Gardens. [Retrieved 5 June 2020]. [acesso em 7 jul 2020]. Disponível em: http:// www.ipni.org 
Jardim Botânico do Rio de Janeiro [Internet]. Flora do Brasil 2020 em construção. [acesso em 7 jul 2020]. Disponível em: http:// floradobrasil.jbrj.gov.br/

Leal L, Biondi D. Potencial ornamental de espécies nativas. Revista Científica Eletrônica de Engenharia Florestal 2006;IV(8).

Lemões MAM, Jacondino M, Ceolin T, Heck RM, Brabieri RL, Machado RA. O uso da planta Sphagneticola trilobata por agricultores acometidos de diabetes mellitus. Revista de Pesquisa Cuidado é Fundamental Online 2012;4(1):2733-2739.

Lewis GP. Legumes of Bahia. Kew: Royal Botanic Gardens; 1987.

Lombardi JA, Morais PO. Levantamento florístico das plantas empregadas na arborização do campus da Universidade Federal de Minas Gerais. Lundiana 2003;4:83-88.

Lorenzi H. Árvores brasileiras, manual de identificação e cultivo de plantas arbóreas do Brasil. v. 1. 4. ed. Nova Odessa: Instituto Plantarum; 2002a.

Lorenzi H. Árvores brasileiras, manual de identificação e cultivo de plantas arbóreas do Brasil. v. 2. 2. ed. Nova Odessa: Instituto Plantarum; 2002b.

Lorenzi H. Árvores brasileiras, manual de identificação e cultivo de plantas arbóreas do Brasil. v. 3. Nova Odessa: Instituto Plantarum; 2009.

Lorenzi H, Matos FJA. Plantas medicinais no Brasil: nativas e exóticas. 2. ed. Nova Odessa: Instituto Plantarum; 2008.

Lorenzi H, Souza HM. Plantas ornamentais no Brasil: arbustivas, herbáceas e trepadeiras. Nova Odessa: Instituto Plantarum; 2015.

Machado RRB, Meunier IMJ, Da Silva JAA, Castro AAJF. Árvores nativas para a arborização de Teresina, Piauí. Revista da Sociedade Brasileira de Arborização Urbana 2006;1(1):10-18. doi: $\underline{10.5380 / \text { revsbau.v1i1.66226 }}$

Martinelli G, Moraes MA. Livro vermelho da flora do Brasil. Rio de Janeiro: Instituto de Pesquisas Jardim Botânico do Rio de Janeiro; 2013.

Martini A, Biondi D, Batista A, Natal C. Fenologia de espécies nativas com potencial paisagístico. Ciências Agrárias 2010;31 (1):75-84.

Matos E, Queiroz LP. Árvores para cidades. Salvador: Solisluna Design; 2009.

Medeiros-Costa JT. Flora Fanerogâmica da Ilha do Cardoso (SP, Brasil): Arecaceae (Palmae). In: Melo MMF, Barros F, Chiea S, Kirizawa M, Mendaçolli SLJ, Wanderley MGL (Eds.). Flora Fanerogâmica da Ilha do Cardoso, v. 10. São Paulo: Instituto de Botânica; 2003. p.57-75.

Miranda GP, Freitas MF, Pasqualetto A, Santos OR, Martins I, Rosa C. Diagnóstico da arborização urbana de Goianira, GO. Anais do III Congresso Brasileiro de Gestão Ambiental; 2012 Nov 19-22; Goiânia. Goiânia: IBEAS; 2012.

MOBOT. Missouri Botanical Garden (1995-2020). [acesso em 7 jul 2020]. Disponível em: http://www.mobot.org/MOBOT/ Research/alldb.shtml

Moreira BP, Lopes SAOR. Espécies nativas com potencial ornamental ocorrentes na bacia do rio Taquarembó, RS. Revista da Jornada de Pós graduação e Pesquisa Congrega Urcamp 2018; 15 (15):579-591

Mounce R, Smith P, Brockington S. Ex situ conservation of plant diversity in the world's botanic gardens. Nature Plants 2017; (3):795-802. doi: 10.1038/s41477-017-0019-3

Oliveira PN, Giulietti AM, Oliveira RP. Flora da Bahia: Iridaceae. Sitientibus série Ciências Biológicas 2016;16:1-38. doi: $10.13102 / \mathrm{scb} 1102$

Ogasawara HA, Roque N. Flora da Bahia: Asteraceae - subtribo Vernoniinae. Sitientibus série Ciências Biológicas 2015;15:1-24. doi: $\underline{10.13102 / \mathrm{scb} 250}$

Peixoto AL, Guedes-Bruni RR. Apresentação: jardins botânicos. Revista Ciência Hoje 2010;30(178):18-19.

Peel MC, Finlayson BL, McMahon TA. Updated world map of the Köppen-Geiger climate classification. Hydrology and Earth Sys- tem Sciences Discussions 2007;4(2):439-473. doi: $10.5194 /$ hess11-1633-2007

Pinto ACR, Graziano TT. Potencial ornamental de curcuma. Revista Brasileira de Horticultura Ornamental 2003;9(2):99-109. doi: $10.14295 /$ rbho.v9i2.173

Pinto AC, Antunes TJ, Santos VC, Costa CBN, Costa JAS. Composição florística de um fragmento de floresta no Corredor Central da Mata Atlântica, sul da Bahia, Brasil. Paubrasilia 2019;2 (2):14-27. doi: $10.33447 /$ paubrasilia.v2i2.22

Queiroz LP. Leguminosae da Caatinga. Feira de Santana/BA: Universidade Estadual de Feira de Santana/Royal Botanic Gardens, Kew/Associação Plantas do Nordeste; 2009.

Randall JM, Reichard S. Roadside use of native plants. Choosing non-invasive plant species - When is it safe to use non-native plants? Washington: U.S. Department of Transportation; 2002.

Randall JM, Marinelli J. Invasive plants, weeds of the global garden. Brooklyn Botanic Garden, Brooklyn, NY; 1996.

Rodolfo Júnior F, Mello R, Cunha TA, Stangerlin DM. Análise da arborização urbana em bairros da cidade de Pombal no estado da Paraíba. Revista da Sociedade Brasileira de Arborização Urbana 2008;3(4):3-19. doi: 10.5380/revsbau.v3i4.66369

Romano CM, Raseira MCB, Neitzke RS, Stumpf ERT, Barbieri RL. Caracterização de genótipos de pessegueiros ornamentais. Magistra 2009;21:268-276.

Salvador. Prefeitura Municipal de Salvador. Manual técnico de arborização urbana de Salvador com espécies nativas da Mata Atlântica. Salvador: Prefeitura Municipal de Salvador/Secretaria da Cidade Sustentável e Inovação-SECIS/Sociedade Brasileira de Arborização-SBAU; 2018.

Schmitz DC, Simberloff D, Hofstetter R, Haller W, Sutton D. The Ecological Impact of Nonindigenous Plants. In: Simberloff D, Schmitz DC, Brown TC. Strangers in paradise. Washington: Island; 1997.

Soares CB, Quental JG. Flores do Jardim Botânico do Rio de Janeiro. Associação de Amigos do Jardim Botânico; 2016.

Souza VC, Flores TB, Lorenzi H. Introdução à botânica: morfologia. São Paulo: Instituto Plantarum de Estudos da Flora; 2013.

Souza VC, Lorenzi H. Botânica sistemática: guia ilustrado para identificação das famílias de Fanerógamas nativas e exóticas no Brasil, baseado em APG IV. 4. ed. Nova Odessa: Instituto Plantarum; 2019.

Stevens PF. Angiosperm Phylogeny Website 2001-2020. Version 14 , July 2017 [and more or less continuously updated since]. [Internet]. [acesso em 7 jul 2020]. Disponível em: http:// www.mobot.org/MOBOT/research/APweb/

Stumpf ERT, Barbieri RL, Heiden G. Cores e formas no Bioma Pampa: plantas ornamentais nativas. Pelotas: Embrapa Clima Temperado; 2009.

Thièrs, B. (continuamente atualizado) [Internet]. Index Herbariorum: the herbaria of the world. [acesso em 6 jul 2020]. Disponível em: http:/ / sweetgum.nybg.org/science/ih/

Tognon GB, Cuquel FL. Potencial ornamental de Baccharis milleflora e Baccharis tridentata como folhagem de corte. Ciência Rural 2016;46(1):70-75. doi: 10.1590/0103-8478cr20150392

Tropicos [Internet]. Tropicos.org. Missouri Botanical Garden. [acesso em 7 Jul 2020]. Disponível em: http://www.tropicos.org

Veiga RFA, Costa AA, Benatti R, Murata IM, Pires EG, Roma RPCR. Os jardins botânicos brasileiros. O Agronômico 2003;55 (1) 56-60.

Veiga, RFA, Tombolato AFC, Costa AA, Barbosa W. Levantamento de plantas ornamentais nativas, mantidas sob conservação $e x$ situ no Brasil. Revista Brasileira de Horticultura Ornamental 2009; 15(1):11-22. doi: $10.14295 /$ rbho.v15i1.430

Vichiato MRM, Vichiato M. Espécies herbáceas e arbustivas ornamentais nativas da flora brasileira em Belo Horizonte Minas Gerais. Revista Tecnologia e Ciência Agropecuária. 2017;11(1):19. 
Vieira RF, Camillo J, Coradin L. Espécies nativas da flora brasileira de valor econômico atual ou potencial: plantas para o futuro: região Centro-Oeste. Série Biodiversidade 44. Brasília: Ministério do Meio Ambiente/Secretaria de Biodiversidade; 2018. Disponível em: https://www.mma.gov.br/publicacoes/biodiversidade/ category/142-serie-biodiversidade.html

Ziller SR. Plantas exóticas invasoras: a ameaça da contaminação biológica. Revista Ciência Hoje 2001;30(178):77-79.

Willison J. Educação ambiental em jardins botânicos: diretrizes para desenvolvimento de estratégias individuais. Ed. cons. Jane Willison. Ed. cons. Jane Greene. Rio de Janeiro: Rede Brasileira de Jardins Botânicos; 2003.

\section{Plantas ornamentales en el Jardín Botánico FLORAS}

Un jardín botánico es un espacio que proporciona conservación ex situ de la biodiversidad, manteniendo plantas vivas. El Jardín Botánico FLORAS JBFLORAS) ocupa el campus Sosigenes Costa (CSC) de la Universidad Federal del Sur de Babia (UFSB) y tiene un remanente de bosque atlántico. El trabajo fue desarrollado en el CSC de la UFSB, en Porto Seguro, Babia, Brasil, área anteriormente ocupada por el Centro Cultural y de Eventos del Descubrimiento. Se realizaron colectas en los jardines del campus y en el bosque de marzo/2017 a febrero/2018. Las plantas fueron herborizadas e incorporadas al herbario Prof. Geraldo C. P. Pinto (GCPP). Se identificaron 86 especies de plantas ornamentales, distribuidas en 78 géneros y 39 familias. Las familias más diversas en número de espécies fueron: Arecaceae y Leguminosae (6 especies); Asparagaceae, Bignoniaceae y Orchidaceae (5 especies); y Araceae, Bromeliaceae, Myrtaceae y Rubiaceae (4 especies). El hábito predominante era berbáceo (29 especies), seguido de arbóreo (25 especies) y arbustivo (20 especies). Se estudiaron 10 especies de plantas nativas con potencial ornamental presente en el fragmento de Bosque Atlántico del JBFLORAS. La mayoría de las especies cultivadas (53,5\%) son de origen exótico y 46,5\% son nativas del bosque atlántico. Se sugiere introducir otras especies nativas a los espacios del Jardín Botánico para enriquecer la conservación ex situ y mejorar el uso de plantas nativas.

Palabras clave: Bosque de tabuleiros. Vegetación. Conservación de la biodiversidad. Conservación ex situ. Plantas potencial ornamental. Flora de Bahia. Bosque remanente. Extremo sur de Babia. Bosque Atlantico.

\section{Plantes ornementales dans les Jardin Botanique FLORAS}

Un jardin botanique est un espace qui assure la conservation ex situ de la biodiversité, en maintenant les plantes en vie. Le jardin botanique FLORAS (JBFLORAS) occupe le campus Sosigenes Costa (CSC) de l'Université fédérale de Babia du Sud (UFSB) et possède un vestige de la forêt atlantique. Le travail a été développé au CSC de l'UFSB, à Porto Seguro, Babia, Brésil, zone précédemment occupée par le Centro Cultural e de Eventos do Descobrimento. Des collectes ont été réalisées dans les jardins du campus et en forêt de mars/2017 à féurier/2018. Les plantes ont été herborisées et incorporées dans l'berbier Prof. Geraldo C.P. Pinto (GCPP). 86 espèces de plantes ornementales ont été identifiées, réparties en 78 genres et 39 familles. Les familles les plus abondantes en nombre d'espèces étaient les suivantes: Arecaceae et Leguminosae (6 espèces); Asparagaceae, Bignoniaceae et Orchidaceae (5 espèces); et Araceae, Bromeliaceae, Myrtaceae et Rubiaceae (4 espèces). L'habitude prédominante était herbacées (29 espèces), suivie par les arboricole (25 espèces) et arbustes (20 espèces). Huit espèces de plantes indigènes à potentiel ornemental présentes dans le fragment de JBFLORAS de la forêt atlantique ont été recensées. La plupart des espèces cultivées (53,5\%) sont d'origine exotique et 46,5\% sont originaires de la forêt atlantique. Il est suggéré d'introduire d'autres espèces indigènes dans les espaces du Jardin botanique afin d'enrichir la conservation ex situ et d'améliorer l'utilisation des plantes indigènes.

Mots clés: Forêt de tabuleiros. Végétation. Conservation de la biodiversité. Conservation ex situ. Plante à potentiel ornemental. Flore de Babia. Reste de la forêt. Extrême sud de Babia. Forêt Atlantique. 